\title{
Surgery for gastric cancer increases plasma levels of vascular endothelial growth factor and von Willebrand factor
}

\author{
Masataka Ikeda ${ }^{1}$, Hiroshi Furukawa ${ }^{2}$, Hiroshi Imamura ${ }^{2}$, Jyunzo Shimizu ${ }^{2}$, Hideyuki Ishida ${ }^{2}$, \\ Seizo Masutani ${ }^{2}$, Masayuki Tatsuta ${ }^{2}$, Takatoshi Kawasaki ${ }^{2}$, and Takashi Satomi ${ }^{2}$ \\ ${ }^{1}$ Department of Surgery and Clinical Oncology (E2), Graduate School of Medicine, Osaka University, 2-2 Yamadaoka Suita, \\ Osaka 565-0871, Japan \\ ${ }^{2}$ Department of Surgery, Sakai Municipal Hospital, Osaka, Japan
}

\begin{abstract}
Background. Angiogenesis and hemostatic activation are important factors in tumor progression and metastasis. Because surgical intervention induces tissue hypoxia and hemostatic activation, we analyzed the effect of gastric surgery on the plasma concentrations of vascular endothelial growth factor (VEGF), soluble P-selectin (sP-selectin), and von Willebrand factor (vWf).

Methods. Plasma VEGF, sP-selectin, and vWf concentrations were measured in 14 patients with gastric cancer before operation and on postoperative day 1 (POD 1). Correlations between disease stage and the effect of surgical intervention were analyzed.

Results. The plasma concentrations of these three factors did not correlate with the disease stage. Plasma levels of sPselectin did not change after operation (before surgery, 87.6 \pm 34.1 ng $/ \mathrm{ml}$; on POD $1,101.1 \pm 48.1 \mathrm{ng} / \mathrm{ml} ; P=0.123)$. Plasma VEGF and $v W f$ concentrations were significantly elevated on POD 1 (VEGF, 33.3 $\pm 20.5 \mathrm{pg} / \mathrm{ml}$ before surgery and $61.9 \pm$ $35.6 \mathrm{pg} / \mathrm{ml}$ on POD 1; $P=0.0013$; vWf, $164 \pm 31.1 \%$ before surgery and $211.1 \pm 66.1 \%$ on POD $1 ; P=0.027$ ).

Conclusion. Because VEGF and vWf are involved in angiogenesis, tumor-platelet adhesion, and tumor-endothelial cell adhesion, surgical intervention could influence tumor growth and metastasis.
\end{abstract}

Key words Gastric cancer · Surgery · Vascular endothelial growth factor · von Willebrand factor · tumor growth and metastasis

\section{Introduction}

Surgical intervention is a typical type of tissue injury. Wound healing requires angiogenesis, which is a key component of the repair mechanisms triggered by tissue

Offprint requests to: $\mathrm{M}$. Ikeda

Received: February 1, 2002 / Accepted: April 9, 2002 injury. Vascular endothelial growth factor (VEGF) is an important mediator of angiogenesis, as it acts directly and specifically on endothelial cells [1]. VEGF, on the other hand, is also a potent tumor growth factor, and elevated levels of circulating VEGF are associated with poor prognosis in many types of malignancies, including gastrointestinal cancers [2-5]. Increased levels of soluble P-selectin (sP-selectin), an adhesion molecule and a component of the membrane of the platelet alpha granule, have been detected in hematological and breast cancers [6], and have been shown to correlate with clinical stage in melanoma [7]. von Willebrand factor (vWf), an adhesive ligand with platelets, has also been shown to be elevated in advanced and disseminated malignancies, such as prostate cancer [8], cervical and ovarian cancer [9], and larynx cancer [10], and it is involved in the metastatic process through the activation of thrombin $[11,12]$.

Because surgical injury induces activation of the coagulation pathway, resulting in the activation of thrombin, platelets, and angiogenesis, we hypothesized that surgery by itself may contribute to promote tumor growth and metastasis via the activation of angiogenic and hemostatic factors such as VEGF, sP-selectin, and $\mathrm{vWf}$. To determine whether circulating VEGF, sPselectin, and $\mathrm{vWf}$ were increased after surgical intervention, we measured the concentrations of VEGF, sP-selectin, and vWf in patients who had undergone gastric surgery.

\section{Subjects and methods}

Plasma-VEGF, sP-selectin, and vWf concentrations were measured in 14 patients (11 men, 3 women) who had undergone surgery at the Sakai Municipal Hospital. All of the patients had gastric cancer. The median age was 61 years (range, 42-74 years). Informed consent was obtained from all the patients, and the study proto- 
Table 1. Clinical characteristics of patients

\begin{tabular}{|c|c|c|c|c|c|c|c|c|}
\hline $\begin{array}{l}\text { Patient } \\
\text { number }\end{array}$ & $\begin{array}{l}\text { Age (years)/ } \\
\text { sex }\end{array}$ & $\begin{array}{l}\text { Depth of } \\
\text { invasion }\end{array}$ & $\begin{array}{c}\text { Regional } \\
\text { lymph nodes }\end{array}$ & $\begin{array}{c}\mathrm{P} \\
\text { factor }\end{array}$ & $\begin{array}{c}\mathrm{H} \\
\text { factor }\end{array}$ & $\begin{array}{c}\mathrm{M} \\
\text { factor }\end{array}$ & $\begin{array}{c}\text { Pathological } \\
\text { stage }\end{array}$ & $\begin{array}{c}\text { Surgical } \\
\text { procedure }\end{array}$ \\
\hline 1 & $61 / \mathrm{M}$ & $\mathrm{T} 2$ & N1 & $\mathrm{P} 0$ & $\mathrm{H} 0$ & M0 & II & DG \\
\hline 2 & $54 / \mathrm{M}$ & $\mathrm{T} 2$ & N2 & $\mathrm{P} 0$ & H0 & M0 & IIIA & $\mathrm{DG}$ \\
\hline 3 & $61 / \mathrm{M}$ & $\mathrm{T} 3$ & N2 & $\mathrm{P} 0$ & H0 & M0 & IIIB & $\mathrm{DG}$ \\
\hline 4 & $70 / \mathrm{M}$ & $\mathrm{T} 2$ & No & $\mathrm{P} 0$ & $\mathrm{H} 0$ & M0 & IB & LS \\
\hline 5 & $53 / \mathrm{M}$ & $\mathrm{T} 1$ & No & $\mathrm{P} 0$ & $\mathrm{H} 0$ & M0 & IA & LS \\
\hline 6 & $68 / \mathrm{M}$ & $\mathrm{T} 1$ & No & $\mathrm{P} 0$ & H0 & M0 & IA & PG \\
\hline 7 & $61 / \mathrm{F}$ & $\mathrm{T} 2$ & N1 & $\mathrm{P} 0$ & $\mathrm{H} 0$ & M0 & II & DG \\
\hline 8 & $42 / \mathrm{M}$ & $\mathrm{T} 1$ & No & $\mathrm{P} 0$ & H0 & M0 & IA & PG \\
\hline 9 & $65 / \mathrm{M}$ & $\mathrm{T} 1$ & N1 & $\mathrm{P} 0$ & Ho & M0 & IB & $\mathrm{DG}$ \\
\hline 10 & $65 / \mathrm{M}$ & $\mathrm{T} 1$ & No & $\mathrm{P} 0$ & $\mathrm{H} 0$ & M0 & IA & PG \\
\hline 11 & $64 / \mathrm{F}$ & $\mathrm{T} 4$ & No & $\mathrm{P} 0$ & H0 & M0 & IIIA & $\mathrm{DG}$ \\
\hline 12 & $42 / \mathrm{M}$ & $\mathrm{T} 1$ & No & $\mathrm{P} 0$ & Ho & M0 & IA & $\mathrm{DG}$ \\
\hline 13 & $55 / \mathrm{F}$ & $\mathrm{T} 1$ & No & $\mathrm{P} 0$ & H0 & M0 & IA & $\mathrm{TG}$ \\
\hline 14 & 74/M & T3 & N3 & $\mathrm{P} 0$ & H0 & CY1 & IV & DG \\
\hline Median & 61 & & & & & & & \\
\hline
\end{tabular}

Clinicopathological factors are according to the criteria of the Japanese Gastric Cancer Association

PG, Partial gastrectomy; DG, distal gastrectomy; TG, total gastrectomy; LS, laparoscopic gastric surgery

col was approved by the institutional review board. The surgical procedure types are listed in Table 1.

Peripheral venous blood was drawn from all the patients and collected into a plastic syringe containing argatroban, a specific thrombin inhibitor, at a final concentration of $20 \mathrm{mM}$. Platelet-poor plasma (PPP) was obtained by centrifugation at $3000 \mathrm{~g}$ for $15 \mathrm{~min}$ and stored at $-80^{\circ} \mathrm{C}$ for the determination of plasma concentrations of VEGF, sP-selectin, and vWf. Because platelets contain a significant amount of VEGF and sP-selectin, we measured the plasma concentrations of VEGF and sP-selectin $[2,13,14]$. Platelet-rich plasma (PRP) was first obtained from blood drawn with citrate or argatroban, and platelet aggregation was induced by thrombin or shear stress before obtaining PPP to determine the platelet activation status. Platelets were quiescent in PRP obtained either with citrate or with argatroban, and platelet aggregability was identical with both agents. In all the patients, a blood sample was obtained before surgery and on postoperative day (POD) 1. The plasma concentrations of $v W f$ were measured by enzyme immunoassay, as previously described [15]. The normal range of vWf was $50 \%-155 \%$. The VEGF levels were measured by a quantitative sandwich enzyme immunoassay technique, using Sf-21-expressed recombinant human VEGF165 (R\&D Systems, Oxford, United Kingdom). This assay detects both VEGF165 and VEGF121. The minimum detectable level of VEGF was $9 \mathrm{pg} / \mathrm{ml}$ and the normal range was less than $38.3 \mathrm{pg} /$ $\mathrm{ml}$. sP-selectin levels were also detected with a sandwich enzyme immunoassay technique, using monoclonal antibody against $\mathrm{P}$-selectin [16]. The minimum detectable level of sP-selectin was $10 \mathrm{ng} / \mathrm{ml}$ and the normal range was $75.9-344 \mathrm{ng} / \mathrm{ml}$. Premedication and anesthetic techniques were similar in all patients. General anesthesia was induced by intravenous thiopental with epidural analgesia injection. Vecuronium bromide was administered for muscle relaxation during surgery, and anesthesia was maintained by ventilation with an $\mathrm{O}_{2} / \mathrm{N}_{2} \mathrm{O}$ mixture and $1 \%-2 \%$ isoflurane.

All values are expressed as means \pm SD. Student's paired $t$-test was used to analyze differences between groups, and a $P$ value less than 0.05 was considered significant. Analysis was performed with StatView 5.0 (SAS Institute, Cary, NC, USA). The staging of gastric cancer and clinicopathological factors used in this study were based on the second English edition of the Japanese classification of gastric carcinoma [17].

\section{Results}

\section{Patient characteristics and clinical outcome}

Table 1 shows the patient characteristics and operational procedures. Of the 14 patients, distal gastrectomy was performed in 9 patients, partial gastrectomy was performed in 3 patients, and laparoscopic surgery was performed in 2 patients. Total gastrectomy with Roux-en Y reconstruction was performed in 1 patient. Postoperative recovery was uneventful in all the patients, except for 1 with anastomotic leakage (patient 10). Four patients died of disease recurrence (patients 2, 3, 11, and 14).

Correlation of VEGF, sP-selectin, and $v W f$ and disease stage

Because concentrations of VEGF, sP-selectin, and vWf have clinical significance in terms of tumor metastasis 
and patient survival $[2-5,18]$, we investigated the relationship between the disease stage and the concentrations of these three markers. The concentration of VEGF in patients with stage IA and IB (group A) was $33.0 \pm 17.1 \mathrm{pg} / \mathrm{ml}$ before operation and $60.2 \pm 36.2 \mathrm{pg} /$ $\mathrm{ml}$ on POD 1 . The concentration of VEGF in patients with stage II and higher (group B) was $33.8 \pm 24.9 \mathrm{pg} / \mathrm{ml}$ before operation and $63.6 \pm 37.7 \mathrm{pg} / \mathrm{ml}$ on POD 1 . The sP-selectin concentration was $83.4 \pm 13.6 \mathrm{ng} / \mathrm{ml}$ before operation and $97.5 \pm 17.3 \mathrm{ng} / \mathrm{ml}$ on POD 1 in group A, and $91.7 \pm 48.0 \mathrm{ng} / \mathrm{ml}$ and $104.7 \pm 68.5 \mathrm{ng} / \mathrm{ml}$ in group $B$, respectively. Differences between groups A and B in terms of VEGF and sP-selectin concentration were not significant. The vWf concentration in group A was 152.6 $\pm 31.0 \%$ before operation and $181.9 \pm 60.5 \%$ on POD 1. That in group B was $176.1 \pm 28.4 \%$ and $240.3 \pm$ $61.7 \%$, respectively. The $\mathrm{vWf}$ concentration in group B was greater than that in group A; however, the difference was not significant.

\section{Effect of gastric surgery on plasma concentrations of} $V E G F$, sP-selectin, and $v W f$

Plasma VEGF concentration was $33.3 \pm 20.5 \mathrm{pg} / \mathrm{ml}$ before surgery and $61.9 \pm 35.6 \mathrm{pg} / \mathrm{ml}$ on POD 1 , which was significantly higher than that before surgery $(P=$ 0.0013; Fig. 1A). Plasma sP-selectin concentration did not change perioperatively (before surgery, $87.6 \pm$ $34.1 \mathrm{ng} / \mathrm{ml}$; POD $1,101.1 \pm 48.1 \mathrm{ng} / \mathrm{ml} ; P=0.123$; Fig. 1B). Plasma vWf concentration was $164 \pm 31.1 \%$ before surgery and $211.1 \pm 66.1 \%$ on POD 1 . The values on
POD 1 were significantly elevated compared with the preoperative values $(P=0.027$; Fig. $1 \mathrm{C})$.

\section{Correlation of VEGF, sP-selectin, and $v W f$ in patients with and without disease recurrence}

In order to confirm our hypothesis that increases in the plasma levels of VEGF, sP-selectin, and vWf are associated with more severe tumor growth, we compared these three markers in patients with and without recurrence. Ten patients were alive without disease recurrence and four patients died of disease recurrence. Plasma levels of VEGF and sP-selectin in patients with recurrence tended to be greater than those without recurrence (Table 2).

\section{Discussion}

In this study we measured the plasma concentrations of VEGF, sP-selectin, and vWf to determine whether surgical intervention could cause tumor growth or metastasis, because these three markers are thought to be involved in angiogenesis, tumor-platelet adhesion, and tumor-endothelial cell adhesion. We found that the plasma VEGF and vWf levels were elevated during the first postoperative day compared with the preoperative levels, suggesting that surgical intervention could influence tumor growth or metastasis.

The development of hematogenous metastasis involves a long series of sequential interrelated steps,

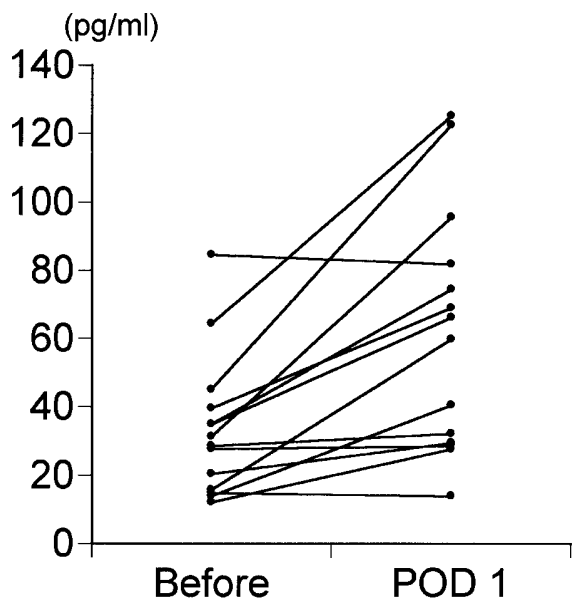

(A)

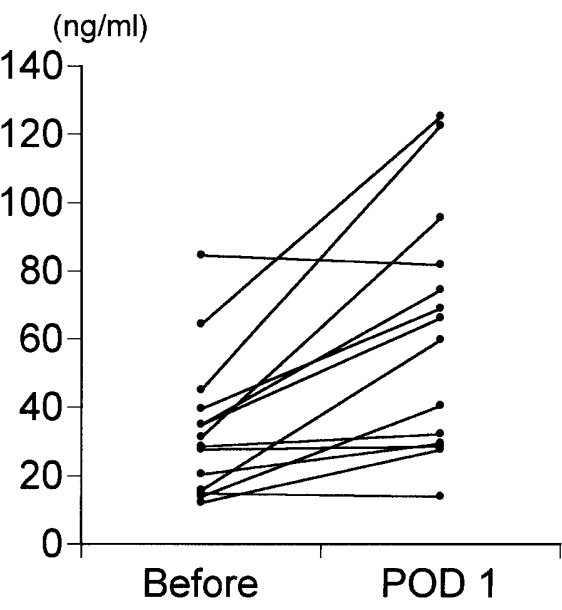

(B)

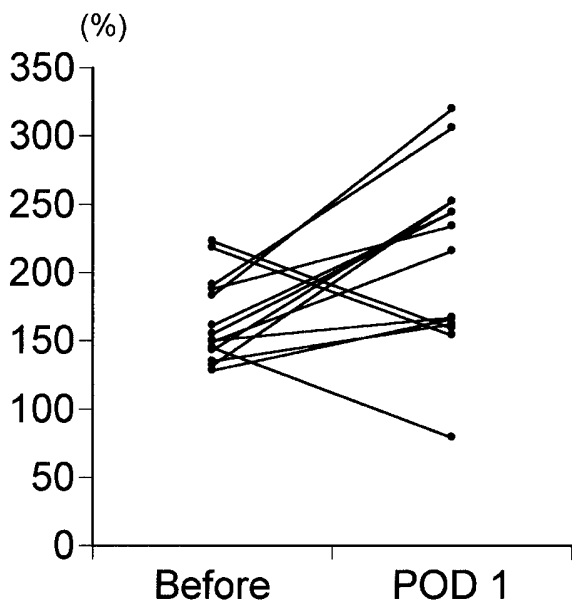

(C)

Fig. 1A-C. Effects of gastric surgery on the plasma concentration of vascular endothelial growth factor (VEGF), soluble Pselectin (sP-selectin), and von Willebrand factor (vWf). Serial changes of $\mathbf{A}$ VEGF, $\mathbf{B}$ sP-selectin, and $\mathbf{C}$ vWf are shown. Plateletpoor plasma obtained with argatroban was collected from 14 patients before surgery (before) and on postoperative day 1 ( $P O D$ 1 ), and plasma concentrations of VEGF, sP-selectin, and vWf were determined as described in "Subjects and methods" 
Table 2. Comparison of the plasma concentrations of VEGF, sP-selectin, and vWf in patients with and without disease recurrence

\begin{tabular}{|c|c|c|c|c|c|c|}
\hline & \multicolumn{2}{|c|}{ VEGF (pg/ml) } & \multicolumn{2}{|c|}{ sP-selectin $(\mathrm{ng} / \mathrm{ml})$} & \multicolumn{2}{|c|}{ vWf (\%) } \\
\hline & Before & POD 1 & Before & POD 1 & Before & POD 1 \\
\hline Patients without recurrence & $29.4 \pm 15.7$ & $57.4 \pm 35.0$ & $77.2 \pm 16.1$ & $88.0 \pm 21.3$ & $158.5 \pm 29.6$ & $215.1 \pm 74.8$ \\
\hline Patients with recurrence & $43.2 \pm 30.0$ & $73.1 \pm 39.5$ & $113.4 \pm 55.1$ & $133.7 \pm 81.8$ & $179.0 \pm 33.8$ & $201.0 \pm 44.2$ \\
\hline$P$ value & 0.27 & 0.48 & 0.07 & 0.11 & 0.29 & 0.73 \\
\hline
\end{tabular}

Values are expressed as means \pm SD

VEGF, Vascular endothelial growth factor; sP-selectin; soluble P-selectin; vWF, von Willebrand factor; POD, postoperative day

including intravasation into the bloodstream, adhesion to vascular endothelial cells of distant organs, tumor cell proliferation, and invasion into the target organ. Recent evidence suggests that platelet-tumor and tumor-endothelial interactions participate in the primary adhesive events required for the initiation of the metastatic process $[12,19]$. vWf and its adhesive ligand, glycoprotein (GP) Ib $\alpha$ on platelets, have been shown to play an important role in the formation of metastasis via tumor-platelet aggregation and thrombus formation $[12,20]$. P-selectin, an adhesion molecule that mediates interactions of platelets, has also been shown to have a crucial role in developing metastasis [21,22]. Although the sP-selectin levels did not change after surgery, we found elevated levels of $\mathrm{vWf}$ and P-selectin expression on platelets $(33.2 \pm 1.6 \%$ before surgery and $40.2 \pm$ $3.7 \%$ on POD $1, n=5 ; P=0.014$ ) after surgery, suggesting that surgical intervention could facilitate hematogenous metastasis if tumor cells were in the bloodstream.

The effect of surgical intervention on VEGF levels has been examined, and major surgery for nonmalignant disease induced the highest transient VEGF increase on POD 1 [23]. Maniwa et al. [24] also showed that pulmonary surgery induced VEGF elevation temporarily in patients with metastatic lung cancer. They also showed, in an animal study, that even only a transient increase of VEGF could cause tumor growth by disrupting the suppression of angiogenesis in dormant micrometastasis early in the postoperative period. These results further support the idea that even only a transient elevation of VEGF can induce tumor metastasis and growth. In order to investigate whether increases in the plasma levels of VEGF, sP-selectin, and vWf were associated with severe tumor growth or poor prognosis, we compared these values in patients with and without recurrence. Although levels of VEGF and sPselectin tended to be greater in patients with disease recurrence, than in patients without recurrence, the difference did not reach significance. This might be because of the small number of patients studied or the short period of follow-up. Studies with larger numbers of patients and longer follow-up are needed.
Metastasis is known to be accompanied by platelet aggregation and activation [12,21,22]. At metastatic sites, it has been suggested that platelets aggregate due to factors released from metastatic cells and direct contact with metastatic cells, resulting in microthrombosis, tumor adhesion, and growth. In this step, VEGF could be released from activated platelets, and this released VEGF could induce the neovascular formation for tumor cell invasion and growth $[13,25]$.

Elevated plasma concentrations of VEGF have been detected in gastric cancer and are closely related to the extent of the disease $[2,5,26]$. Compared with the VEGF concentrations in healthy controls $(n=20)$, VEGF concentrations in 4 patients were elevated, 2 of whom were stage IV patients. However, we found no significant correlation between VEGF and disease stage in the present study. This might be because of the small number of patients studied. Higher levels of VEGF are found in patients with advanced stage or metastatic disease, suggesting that VEGF is released from tumor tissues [27]. In fact, elevated levels of VEGF were observed in 2 stage IV patients. The VEGF increase in the present study, however, was derived not only from tumors, because most of the tumors were resected during surgery and VEGF is rapidly cleared from the circulation as a heparin-binding protein (half-life is less than $3 \mathrm{~min}$ ), even though VEGF may be released from the tumors due to surgical manipulation [28]. Platelets and leukocytes have been shown to contain significant amounts of angiogenic factors, including VEGF $[13,25,29]$, suggesting that the elevation of VEGF after surgery is mainly from platelets and leukocytes. Therefore, inhibition of the activation of platelets or leukocytes is of clinical value in preventing tumor growth or metastasis.

In conclusion, surgical intervention in gastric cancer induces the elevation of plasma vWf and VEGF concentrations, which not only stimulates the proliferation of tumor vascularization and increasing vascular permeability but also induces tumor adhesion to endothelial cells, contributing to tumor-cell extravasation and metastasis formation. Therefore, surgical intervention could cause the development and dissemination of gas- 
tric cancer cell metastasis. The potential roles of surgical intervention in tumor growth and metastasis need to be examined.

\section{References}

1. Conn G, Soderman DD, Schaeffer MT, Wile M, Hatcher VB, Thomas KA. Purification of a glycoprotein vascular endothelial cell mitogen from a rat glioma-derived cell line. Proc Natl Acad Sci USA 1990;87:1323-7.

2. Hyodo I, Doi T, Endo H, Hosokawa Y, Nishikawa Y, Tanimizu $\mathrm{M}$, et al. Clinical significance of plasma vascular endothelial growth factor in gastrointestinal cancer. Eur J Cancer 1998;34: 2041-5.

3. Takeda A, Shimada H, Imaseki H, Okazumi S, Natsume T, Suzuki T, et al. Clinical significance of serum vascular endothelial growth factor in colorectal cancer patients: correlation with clinicopathological factors and tumor markers. Oncol Rep 2000;7: 333-8.

4. Kumar H, Heer K, Lee PW, Duthie GS, MacDonald AW, Greenman J, et al. Preoperative serum vascular endothelial growth factor can predict stage in colorectal cancer. Clin Cancer Res 1998;4:1279-85.

5. Kitamura M, Toi M, Arai K, Iwasaki Y, Suzuki H, Matsuo K. Concentrations of vascular endothelial growth factor in the sera of gastric cancer patients. Oncol Rep 1998;5:1419-24.

6. Blann AD, Gurney D, Wadley M, Bareford D, Stonelake P, Lip GYH. Increased soluble P-selectin in patients with haematological and breast cancer: a comparison with fibrinogen, plasminogen activator inhibitor and von Willebrand factor. Blood Coagul Fibrinolysis 2001;12:43-50.

7. Schadendorf D, Diehl S, Zuberbier T, Schadendorf C, Henz BM. Quantitative detection of soluble adhesion molecules in sera of melanoma patients correlates with clinical stage. Dermatology 1996;192:89-93.

8. Ablin RJ, Bartkus JM, Gonder MJ. Immunoquantitation of factor VIII-related antigen (von Willebrand factor antigen) in prostate cancer. Cancer Lett 1988;40:283-9.

9. Gadducci A, Baicchi U, Marrai R, Facchini V, del BB, Fosella PV, et al. Pretreatment plasma levels of fibrinopeptide-A (FPA), D-dimer (DD), and von Willebrand factor (vWF) in patients with operable cervical cancer: influence of surgical-pathological stage, tumor size, histologic type, and lymph node status. Gynecol Oncol 1993;49:354-8.

10. Paczuski R, Bialkowska A, Kotschy M, Burduk D, Betlejewski S. Von Willebrand factor in plasma of patients with advanced stages of larynx cancer. Thromb Res 1999;95:197-200.

11. Nierodzik ML, Klepfish A, Karpatkin S. Role of platelets, thrombin, integrin IIb-IIIa, fibronectin and von Willebrand factor on tumor adhesion in vitro and metastasis in vivo. Thromb Haemost 1995;74:282-90.

12. Oleksowicz L, Dutcher JP. Adhesive receptors expressed by tumors and platelets: novel targets for therapeutic anti-metastatic strategies. Med Oncol 1995;12:95-102.
13. Banks RE, Forbes MA, Kinsey SE, Stanley A, Ingham E, Walters $\mathrm{C}$, et al. Release of the angiogenic cytokine vascular endothelial growth factor (VEGF) from platelets: significance for VEGF measurements and cancer biology. Br J Cancer 1998;77:95664.

14. Jelkmann W. Pitfalls in the measurement of circulating vascular endothelial growth factor. Clin Chem 2001;47:617-23.

15. Bartlett A, Dormandy KM, Hawkey CM, Stableforth P, Voller A. Factor-VIII-related antigen: measurement by enzyme immunoassay. BMJ 1976;1:994-6.

16. Katayama M, Handa M, Ambo H, Araki Y, Hirai S, Kato I, et al. A monoclonal antibody-based enzyme immunoassay for human GMP-140/P-selectin. J Immunol Methods 1992;153:41-8.

17. Japanese Gastric Cancer Association. Japanese classification of gastric carcinoma. 2nd English Ed. Gastric Cancer 1998;1:1024.

18. Yamamoto Y, Toi M, Kondo S, Matsumoto T, Suzuki H, Kitamura M, et al. Concentrations of vascular endothelial growth factor in the sera of normal controls and cancer patients. Clin Cancer Res 1996;2:821-6.

19. Gasic R. Role of plasma, platelets and endothelial cells in tumor metastasis. Cancer Metastasis Rev 1984;3:99-116.

20. Oleksowicz L, Bhagwati N, DeLeon FM. Deficient activity of von Willebrand's factor-cleaving protease in patients with disseminated malignancies. Cancer Res 1999;59:2244-50.

21. Kim YJ, Borsig L, Varki NM, Varki A. P-selectin deficiency attenuates tumor growth and metastasis. Proc Natl Acad Sci USA 1998;95:9325-30.

22. Borsig L, Wong R, Feramisco J, Nadeau DR, Varki NM, Varki A. Heparin and cancer revisited: mechanistic connections involving platelets, P-selectin, carcinoma mucins, and tumor metastasis. Proc Natl Acad Sci USA 2001;98:3352-7.

23. Bondestam J, Salven P, Jaaskela SH, Ikonen T, Lepantalo M, Mattila S, et al. Major surgery increases serum levels of vascular endothelial growth factor only temporarily. Am J Surg 2000;179: 57-9.

24. Maniwa Y, Okada M, Ishii N, Kiyooka K. Vascular endothelial growth factor increased by pulmonary surgery accelerates the growth of micrometastases in metastatic lung cancer. Chest 1998; 114:1668-75.

25. Gunsilius E, Petzer A, Stockhammer G, Nussbaumer W, Schumacher P, Clausen J, et al. Thrombocytes are the major source for soluble vascular endothelial growth factor in peripheral blood. Oncology 2000;58:169-74.

26. Eroglu A, Demirci S, Ayyildiz A, Kocaoglu H, Akbulut H, Akgul $\mathrm{H}$, et al. Serum concentrations of vascular endothelial growth factor and nitrite as an estimate of in vivo nitric oxide in patients with gastric cancer. Br J Cancer 1999;80:1630-4.

27. Kondo S, Asano M, Matsuo K, Ohmori I, Suzuki H. Vascular endothelial growth factor/vascular permeability factor is detectable in the sera of tumor-bearing mice and cancer patients. Biochim Biophys Acta 1994;1221:211-4.

28. Isner JM, Asahara T. Therapeutic angiogenesis. Front Biosci 1998;3:449-69.

29. Salven P, Orpana A, Joensuu H. Leukocytes and platelets of patients with cancer contain high levels of vascular endothelial growth factor. Clin Cancer Res 1999;5:487-91. 